\title{
Studies on Design and Fabrication of Polymer Based Composite Materials with Fish Scale Reinforcement
}

\author{
Animesh Borah ${ }^{1}$, Duniwanhi Suchiang ${ }^{2}$, Kallol Debnath ${ }^{3}$, \\ Md. Murtaza Alam ${ }^{4}$, Manapuram Muralidhar ${ }^{5}$ \\ 1,2,3,4,5 (Department of Mechanical Engineering, North Eastern Regional Institute of Science and Technology, \\ Nirjuli, Itanagar, Arunachal Pradesh, India)
}

\begin{abstract}
Globally, around 80,000 metallic and non-metallic materials have been developed by scientists, engineers and technologists. However, various properties required for suitable applications need to explore newer materials. Composite materials have been developed based on this requirement. Natural fibers include vegetable, mineral and animal fibers. In India, the large number of natural fibers is not utilized properly. In India, fish production 95.7 lakhs of tonnes out of which 7.34 lakhs of tonnes of fish scale is produced every year but unutilized. In the present work, an attempt has been made to design, develop and explore the possibility of utilization of fish scale in the form of flakes or short fibers in polymer composites. This bio-waste is used for fabrication of LAPOX L12 resin based composites. The fabrication setup for composite materials has been developed and fabricated for hand layup technique. Composites with different orientations have been fabricated. Several useful conclusions have been arrived at.
\end{abstract}

Keywords: animal fiber, composite materials, fish scale composites, hand lay-up technique, Labeo Rohita .

\section{INTRODUCTION}

Globally, a large number of materials 40,000 metallic materials and 40,000 more non-metallic materials, have been developed by scientists, engineers and technologists. However various properties required for suitable applications need to explore newer materials. Composites are evolved based on the requirement. In India, natural fibers such as bamboo, banana, coir, hemp, kenaf, jute, pineapple, sisal, ramie etc. are available in abundant. Millions of tons [1] of animal fibers like fish scale, scrub shells, tortoise shells are produced annually as well. Unfortunately, most of their wastes do not have any useful utilization or has been used to a limited extent. Hence, focus should be on the development of animal fiber composites basically to explore value-added application possibilities. Such composites have recently gained attention [2] due to low cost, low density, acceptable specific properties, ease of separation, enhanced energy recovery, $\mathrm{CO}_{2}$ neutrality, biodegradability and recyclable nature.

'Compositus' is a Latin word from which the word 'composite' is derived. It means 'put together' signifying something made by putting together different parts or materials. Composites [3] are the combination of reinforcing phase and matrix phase. Fibers or particles called reinforcing phase are embedded in matrixphase. In general, composites are materials which consist of two or more physically distinct and mechanically separable components, existing in two or more phases. The main function of the matrix is to transfer stresses between the reinforcing fibers and protect the material from mechanical or environmental damage. The presence of fibers [4] in increases the mechanical properties such as strength, stiffness, flexural strength etc. in a composite. The mechanical properties of composites are superior to those of its individual constituents, and in some cases may be unique for specific properties.

Fabricating the composites by hand-lay-up technique is simple and cost effective. Since, the experimental set up is easy to fabricate and manufacturing of the composites. This paper overviews design and development of polymer based composite materials with fish scale reinforcement. Minimum void should be present in the fabricated composites. Otherwise, their expected properties would be downgraded. Presence of void upto $2 \%$ in a fabricated composite material can be considered to be good. Curing time, adhesion between matrix and reinforcement material (flakes of fish scale) and volume fraction of flakes are very decisive factors for mechanical characteristics of composite materials. 


\section{LITERATURE SURVEY}

To highlight the importance of this present study, possible background information and past related works on polymer composites are surveyed. In this survey primary focus was on the progress of fish scale in the development of polymer composites.

According to the department of animal husbandry, dairying and fisheries of India, the total fish production [5] in India during 2013-14 was 9.58 metric ton. This status shows an increase of 5.96 per cent in fish production over 2012-13. For this study, fish scales were collected from two different sources i.e. fish markets of Nirjuli and Naharlagun, situated in the state of Arunachal Pradesh, India. Each sample of scales was collected from 1kilogram of fish. Average of each samples were calculated to estimate the fish scales available from each kilogram of fish. For each kilogram of fish, we get approximately 76.67 gram of fish scales. The estimated fish scale waste for a period of five years is presented in Table 1.

TABLE I. Fish Production and Fish Scale of India for 5 years period

\begin{tabular}{|c|c|c|}
\hline Year & Fish Production (Thousand Tonnes) & Available Fish Scale (Tonnes) \\
\hline $2009-10$ & 7914 & 606.767 \\
\hline $2010-11$ & 8400 & 644.028 \\
\hline $2011-12$ & 8700 & 667.029 \\
\hline $2012-13$ & 9040 & 693.096 \\
\hline $2013-14$ & 9579 & 734.422 \\
\hline
\end{tabular}

Fish scales are the external derivatives of fish body. They are treated as a waste material. But they can be converted into value added products. Scales are the skeletal elements that cover and protect the skin of fishes. Basically they are plywood-like structures of closely packed collagen fiber layers reinforced with a mineral phase of calcium-deficient hydroxyapatite. Fish scales [6] have characteristics that are also found in other structures such bones, teeth and mineralized tendons. All these materials [7] are formed by an organic component (i.e. collagen), a mineral component (i.e. hydroxyapatite) and water.

Alok Satapathy et al. (2009) [8] developed a composite by using short flakes of fish scales and embedded them into epoxy resin. A commonly found fresh water fish called Labeo rohita was considered for making the composite. The processing, characterization and erosion wear characteristics of the fabricated composites were studied. They concluded that these composites possess very low amount of porosity and improved micro-hardness. They exhibit slightly inferior tensile and flexural strengths than those of the neat polymer.

Ashley Browning et al. (2013) [9] studied about mechanics of composite elasmoid fish scale assemblies and their bio-inspired analogues. Fish scales form a natural flexible armour which protects underlying soft tissue and vital organs. They concluded that deformation mechanisms of scale bending, scale rotation, tissue shear and tissue constraint are responsible for the ability of the composite to protect the underlying substrate. Overlapping scale units distribute stresses across a large volume of material and provide penetration resistance at a reduced weight (and subsequent cost of mineralization) compared to a continuous armor layer. Highly overlapping scales are beneficial as they provide multiple layers of defense.

Vincent R. Sherman et al. (2014) [10] studied about the scales of the arapaima (Arapaima gigas). It is considered as one of the largest freshwater fish in the world. The structure of the arapaima scales and the functions of the different layers were studied. Focus was given on the mechanical behavior, including tension and penetration of the scales, with and without the highly mineralized outer layer.

Pradhan A K (2011) [11] investigated processing, characterization and erosion wear behavior of biofiber reinforced polymer composites. Polymer composites were fabricated with or without using two particulate fillers i.e. silicate carbide and fly ash. Effects of these particulate fillers are studied in terms of erosion characteristics. These fillers were responsible for modification of tensile, flexural and impact strength of the polymer composites. 


\section{RAW MATERIALS}

Quality of new composite material is dependent upon the raw materials used and the processing techniques to fabricate the new materials. Raw materials used in this experimental work are: fish scales, epoxy resin and hardener.

\subsection{FISH SCALES}

The fish scales are collected from the fish markets of Nirjuli and Naharlagun, located in the state of Arunachal Pradesh, India. Labeo rohita (common local name is rohu) was chosen for present study as it is easily available. This is a typical fresh water fish and can be identified by the dark scales present on its upper body. Fish scales are washed by water to remove dust and impurities from their surface. They are kept in sunlight to dry and are allowed to become crispy. The dimensions of collected fish scales like major axis, minor axis, surface area and their classification are presented in Table 2 and their shapes are shown in Figure 1. Fish scales (short, medium, and large) are converted into short flakes. Short flakes are used as the reinforcing material.

TABLE II. Fish Scale Dimensions and Classification

\begin{tabular}{|c|c|c|c|c|c|c|}
\hline $\begin{array}{l}\text { Specimen } \\
\text { No. }\end{array}$ & $\begin{array}{l}\text { Major Axis } \\
\text { (in mm) }\end{array}$ & $\begin{array}{l}\text { Minor Axis } \\
\text { (in mm) }\end{array}$ & $\begin{array}{c}\text { Surface Area } \\
\left(\text { in } \mathrm{mm}^{2}\right)\end{array}$ & $\begin{array}{c}\text { Category } 1 \\
\left(>150 \mathrm{~mm}^{2}\right)\end{array}$ & $\begin{array}{c}\text { Category 2 } \\
\left(100-150 \mathbf{m m}^{2}\right)\end{array}$ & $\begin{array}{c}\text { Category } 3 \\
\left(<100 \mathrm{~mm}^{2}\right)\end{array}$ \\
\hline 01 & 21 & 15 & 178 & $\checkmark$ & & \\
\hline 02 & 20 & 12 & 169 & $\checkmark$ & & \\
\hline 03 & 19 & 13 & 193 & $\checkmark$ & & \\
\hline 04 & 21 & 12 & 156 & $\checkmark$ & & \\
\hline 05 & 21 & 13 & 136 & & $\checkmark$ & \\
\hline 06 & 20 & 13 & 166 & $\checkmark$ & & \\
\hline 07 & 20 & 15 & 170 & $\checkmark$ & & \\
\hline 08 & 20 & 15 & 199 & $\checkmark$ & & \\
\hline 09 & 17 & 13 & 191 & $\checkmark$ & & \\
\hline 10 & 16 & 10 & 132 & & $\checkmark$ & \\
\hline 11 & 18 & 13 & 160 & $\checkmark$ & & \\
\hline 12 & 17 & 10 & 215 & $\checkmark$ & & \\
\hline 13 & 18 & 13 & 062 & & & $\checkmark$ \\
\hline 14 & 18 & 11 & 092 & & & $\checkmark$ \\
\hline 15 & 17 & 11 & 133 & & $\checkmark$ & \\
\hline 16 & 18 & 12 & 116 & & $\checkmark$ & \\
\hline 17 & 18 & 13 & 167 & $\checkmark$ & & \\
\hline 18 & 17 & 12 & 161 & $\checkmark$ & & \\
\hline 19 & 18 & 11 & 164 & $\checkmark$ & & \\
\hline 20 & 14 & 09 & 104 & & $\checkmark$ & \\
\hline 21 & 11 & 08 & 098 & & & $\checkmark$ \\
\hline 22 & 15 & 09 & 167 & $\checkmark$ & & \\
\hline 23 & 16 & 12 & 163 & $\checkmark$ & & \\
\hline 24 & 15 & 09 & 164 & $\checkmark$ & & \\
\hline 25 & 15 & 08 & 139 & & $\checkmark$ & \\
\hline 26 & 15 & 09 & 083 & & & $\checkmark$ \\
\hline 27 & 13 & 08 & 134 & & $\checkmark$ & \\
\hline 28 & 12 & 09 & 154 & $\checkmark$ & & \\
\hline 29 & 14 & 08 & 209 & $\checkmark$ & & \\
\hline 30 & 13 & 10 & 114 & & $\checkmark$ & \\
\hline
\end{tabular}



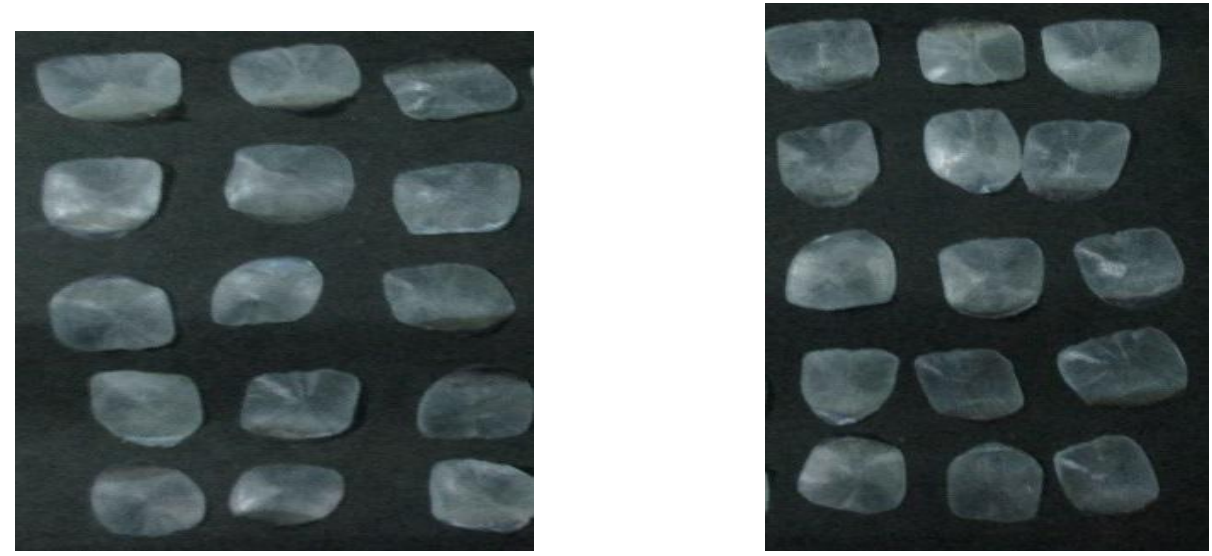

Fig 1: Fish Scale of two different sizes

IV. DESIGN OF RESIN BASED Fish SCALE COMPOSITE MATERIALS

The composite materials design and development includes selection of matrix material (resin and hardener), reinforcement materials and fabrication methods.

\subsection{MATRIX MATERIALS}

Polymer matrices are commonly used because of cost efficiency, ease of fabricating complex parts with less tooling cost. They also have excellent room temperature properties when compared to metal and ceramic matrices. Epoxy resin properties [12-13] are presented in Table 3. Fish scale in flake form and raw fish scales are shown in figure 1 and fabricated resin matrix fish scale reinforced composites are shown in figures 2 and 3.

\subsection{EPOXY RESIN AND HARDENER}

Epoxy resins [14] provide excellent adhesion to wide variety of fibers. Hence, they are chosen to be used for fabrication of proposed composites. The viscosity of conventional epoxy resins is higher and exhibit low shrinkage upon curing. The cured resins have high chemical, corrosion resistance, good mechanical and thermal properties and good performance at elevated temperatures.

Combination of Epoxy resin (Lapox L12) and hardener (K-6) is chosen for this present study. Since, this particular matrix polymer provides good resistance to alkalis and has good adhesive properties. Resin and hardener are provided by HARIPA India Ltd. Kolkata, having following properties as given in TABLE 3.

TABLE III. Resin Matrix Materials and Properties

\begin{tabular}{|l|l|l|}
\hline \multicolumn{1}{|c|}{ Properties } & \multicolumn{1}{c|}{ Resin } & \multicolumn{1}{c|}{ Hardener } \\
\hline Trade Name & LAPOX L12 & K-6 \\
\hline Chemical Name & Diglycidyl Ether bisphnol (DGEBA) & TryethylelTetramine (TETA) \\
\hline Density & $1120 \mathrm{~kg} / \mathrm{m}^{3}$ & $954 \mathrm{~kg} / \mathrm{m}^{3}$ \\
\hline
\end{tabular}

\section{FABRICATION OF FISH SCALE REINFORCED RESINCOMPOSITE MATERIAL}

Simple hand lay-up technique is used for fabrication of the composite. It is one of the commonly used methods to fabricate composites or reinforced products.

- A mould is fabricated by using MS Steel angle $(25 \mathrm{~mm}$ X $25 \mathrm{~mm})$ and mild steel plate $(400 \mathrm{~mm} \mathrm{X}$ $400 \mathrm{~mm}$ X $5 \mathrm{~mm}$ thick). A composite of dimension $350 \mathrm{~mm}$ X $200 \mathrm{~mm}$ can be prepared by using this mould by hand layup method.

- Epoxy Resin (LAPOX L12) and corresponding hardener (K6) are mixed in a ratio of 10:1 by weight as recommended.

- The dried fish scales are converted into flakes and three pre-determined weight proportions $(5,10,15$ wt $\%$ ) are considered for reinforcement. The amount of matrix material and reinforcement used in the polymer composite are given in tabulated form in Table 4. 
- Flakes of fish scales are reinforced into the epoxy resin with random orientation. The resin mixed with hardener and the short flakes are thoroughly mixed.

- Prepared paste is spread on a sheet by a using a roller of $350 \mathrm{~mm}$ length X $40 \mathrm{~mm}$ diameter.

- To prevent air entrapment during fabrication, special care has been taken.

- When the desired thickness is achieved (about $6 \mathrm{~mm}$ ), the mold is then covered by a thin plastic sheet. A load of about $20-25 \mathrm{~kg}$ is kept above it in order to avoid any distortion during shrinkage.

- Each composite is cured at room temperature for 20-24 hours without applying any external heat. This time allows the resin matrix to develop the required strength.

TABLE IV. Samples of different compositions with quantities of matrix material and reinforcement

\begin{tabular}{|c|c|c|c|c|c|}
\hline \multirow{2}{*}{ Samples / Composition } & \multicolumn{2}{|c|}{ Resin } & \multicolumn{2}{c|}{ Hardener } & $\begin{array}{c}\text { Flakes of } \\
\text { Fish Scale }\end{array}$ \\
\cline { 2 - 6 } & Weight (gm) & Volume (ml) & Weight (gm) & Volume (ml) & Weight (gm) \\
\hline PC1 (Matrix + 5 wt\% FS) & 400 & 360 & 40 & 42 & 22 \\
\hline PC2 (Matrix + 10 wt\% FS) & 350 & 315 & 35 & 38 & 38.5 \\
\hline PC3 (Matrix + 15 wt\% FS) & 330 & 295 & 33 & 35 & 54.5 \\
\hline
\end{tabular}
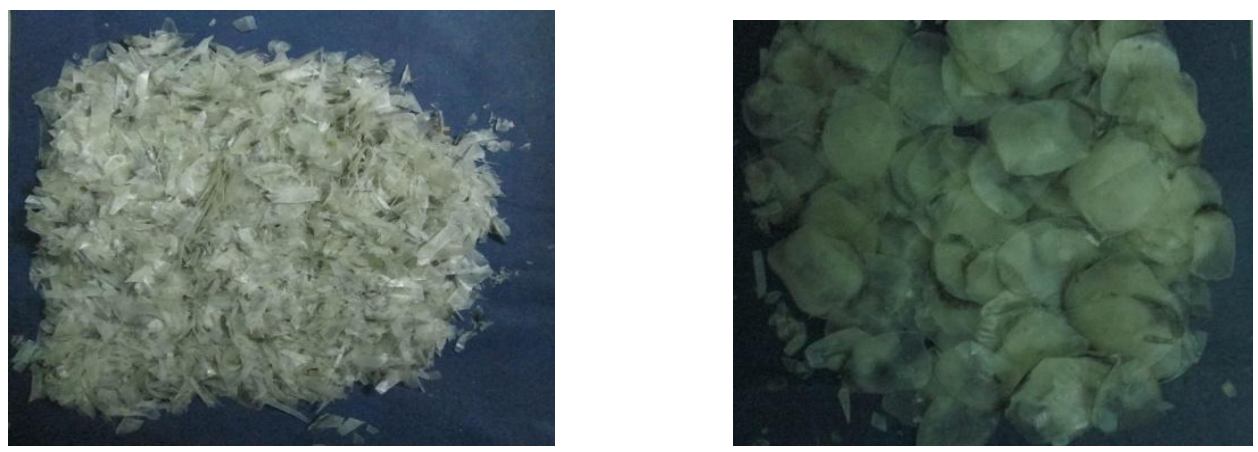

Fig 2: Flakes of Fish Scales and Fish scales before fabrication
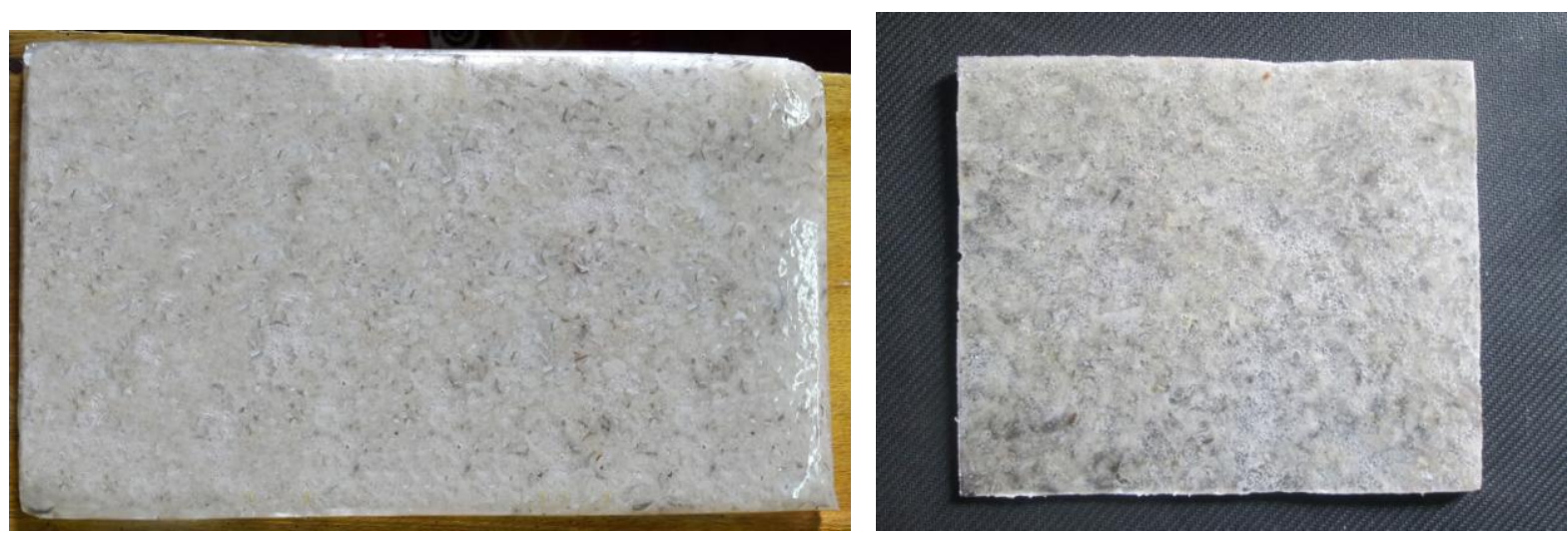

Fig 3: Epoxy Resin based Fish Scale Reinforced Composites after fabrication

\section{CONCLUSION}

Natural bio-fiber based resin based fish scale reinforced composite materials were designed and fabricated with random orientations of the flakes. Annual quantities of fish scale availability were quantified for a period of five years. Design and fabrication of hand lay-up set up for fabrication of composites was done. A 
stepwise procedure for hand layup technique was developed for fabrication of composites. The fabricated composites are bio-degradable and have engineering applications for better wear out properties.

\section{Acknowledgements}

The authors gratefully acknowledge the necessary help rendered by Department of Mechanical Engineering, North Eastern Regional Institute of Science and Technology, Nirjuli, Itanagar, Arunachal Pradesh, India.

\section{REFERENCES}

[1] D. Verma, P.C. Gope, M.K. Maheshwari and R.K. Sharma, "Bagasse Fiber Composites - A Review", J. Mater. Environ. Sci. 3 (6), 2012.

[2] M. Reddy H, Bharath S Kodli, Ravi B Chikmeti, "Experimental investigation of mechanical properties of sisal fiber and rice husk reinforced polymer composite", 11(4), 2014, 05-11.

[3] D. Das, B. Pourdeyhimi, "Composite Nonwoven Materials: Structure, Properties and Applications", Woodhead Publising, Cambride, 2014.

[4] D. J. David, A. Misra, Relating Materials Properties to Structure, (Technomic Publication: Pennsylvania, 1999).

[5] Economic Survey 2014-15 Statistical Appendix, Government of India, Ministry of Finance, Department of Economics Affairs, Economic Division, 2015.

[6] O.P Troncoso and F.G. Torres, "The Nanocomposite Laminate structure in fish Scales from Arapaima Gigas", Proc. $2^{\text {nd }}$ Int. Conf. and Exhibtion on Materials Science and Engineering, 2013.

[7] T Ikoma, H Kobayashi, J Tanaka, D Walsh and S Mann, "Microstructure, mechanical, biomimetic properties of fish scales from Pagrus majo", Journal of Structural Biology, 142, 2003, 327-333.

[8] A. Satapathy, A. Patnaik, M. K. Pradhan, "A study on processing, characterization and erosion behavior of fish (Labeo-rohita) scale filled epoxy matrix composites", Materials and Design, 30, 2009, 2359-2371.

[9] A. Browning, C. Ortizb, M. C. Boyce, "Mechanics of composite elasmoid fish scale assemblies and their bioinspired analogues", Journal of the Mechanical Behavior of Biomedical Materials, 19, 2013, 75-86.

[10] W. Yang, V.R. Sherman, B.Gludovatz, M. Mackey, E. A. Zimmermann, E.H. Chang, E.Schaible, Z. Qin, M.J. Buehler, R. O. Ritchie and M.A. Meyers, "Protective role of Arapaima gigas fish scales: Structure and mechanical behaviour", Acta Biomaterialia, 10(8), 2014, 3599-3614.

[11] A.K. Pradhan, "Processing, Characterization and Erosion wear behaviour of a New Class Bio-Fiber Reinforced Polymer Composites", Ph. D Dissertation, Sambalpur University, Burla, Orissa, August 2011.

[12] H B Vinay, H K Govindaraju, P. Banakar, "Processing and Characterization of Glass Fiber and Carbon Fiber Reinforced Vinyl Ester Based Composites", International Journal of Research in Engineering and Technology, 4(5), 2015, 401-406.

[13] Alok Kumar Rathore, Amit Kumar Kachhawaha and Harsh Pandey, "Flexural Failure Analyse on Banana Fibers Reinforced Polymer Composites", Journal of Harmonized Research (JOHR), 3(2), 2015, 85-88.

[14] N. Naveena, M. Ranjitham, "Numerical Study on Retrofitting of Beam Column Joint Strengthened with CFRP", International Journal of Research in Engineering and Technology, 3(1), 2016, 914-920. 